\title{
Upregulation of the miR-212/132 cluster suppresses proliferation of human lung cancer cells
}

\author{
XIN JIANG $^{1 *}$, XIALIN CHEN $^{2 *}$, LING CHEN $^{1 *}$, YAN MA $^{1}$, LINYAN ZHOU $^{3}$, QIUFENG QI $^{4}$, \\ YONGPING LIU ${ }^{4}$, SHUYU ZHANG ${ }^{5}$, JUDONG LUO ${ }^{1}$ and XIFA ZHOU ${ }^{1}$ \\ ${ }^{1}$ Department of Radiotherapy, Changzhou Tumor Hospital, Soochow University, Changzhou, Jiangsu 213001; \\ ${ }^{2}$ Department of Oncology, Shaoxing People's Hospital, Zhejiang University, Shaoxing, Zhejiang 312000; \\ ${ }^{3}$ Department of Pathology, ${ }^{4}$ Tumor Laboratory, Changzhou Tumor Hospital, Soochow University, Changzhou, \\ Jiangsu 213001; ${ }^{5}$ School of Radiation Medicine and Protection and Jiangsu Provincial Key Laboratory \\ of Radiation Medicine and Protection, Soochow University, Suzhou, Jiangsu 215123, P.R. China
}

Received September 2, 2014; Accepted November 12, 2014

DOI: $10.3892 /$ or.2014.3637

\begin{abstract}
Lung cancer is the leading cause of cancer-related mortality worldwide. microRNAs (miRNAs) are small posttranscriptional regulatory non-coding RNAs that function as oncogenes or tumor suppressors in human cancers. Emerging evidence reveals that deregulation of miRNAs contributes to the progression of human lung cancer, which is the leading cause of cancer-related deaths worldwide. In the present study, we found that upregulation of the miR-212/132 cluster significantly suppressed the growth and focus formation of A549 and H1299 cells. Moreover, forced expression of this cluster conferred radiosensitivity and inhibited the migration of lung cancer cells, whereas downregulation of miR-212/132 reversed the above effects. Furthermore, miR-212/132 overexpression induced cell cycle arrest at the G1/S phase transition of the lung cancer cells, and inhibition of miR-132 and miR-212 abrogated this arrest. In addition, miR-212/132 overexpression increased the percentage of cells undergoing apoptosis. Cells transfected with the miR-212/132 cluster exhibited upregulated p21 expression and reduced cyclin D1 expression. Conversely, cells transfected with the miR-212/132 inhibitor showed reduced expression of p21 and upregulated expression of cyclin D1, suggesting that miR-212/132 may mediate proliferation and cell cycle arrest through $\mathrm{p} 21$ and cyclin D1. Our study provides insight into the biological function of the miR-212/132 cluster in lung cancer. The present study may provide a potential therapeutic target for the treatment of lung cancer.
\end{abstract}

Correspondence to: Dr Xifa Zhou or Dr Judong Luo, Department of Radiotherapy, Changzhou Tumor Hospital, Soochow University, 1 North Huaide Road, Zhonglou, Changzhou, Jiangsu 213001, P.R. China

E-mail: 83559808@qq.com

E-mail: judongluo@gmail.com

${ }^{*}$ Contributed equally

Key words: lung cancer, miR-212/132, proliferation, radiosensitivity

\section{Introduction}

Lung cancer is the leading cause of cancer-related mortality among males worldwide, and the second leading cause of cancer-related deaths among females, ranking second to only breast cancer (1). Non-small cell lung cancer (NSCLC) and small cell lung cancer are the main types of lung cancer according to histologic classification, with NSCLC accounting for $\sim 80-85 \%$ of all lung cancer cases (2). Cigarette smoking and air pollution have been proven to be the main causative factors of lung cancer. Patients with lung cancer usually are diagnosed in advanced stages, and most of lung cancer commonly metastasizes to the brain, bones, liver and adrenal glands (3). Although there are many common treatments, including surgery, chemotherapy and radiotherapy, the survival rates of lung cancer patients are still very low and recurrence risk is high.

Genetic and epigenetic changes have been shown to play important roles in the formation and progression of multiple types of cancers, including the silencing of tumor suppressors, overexpression of oncogenes and changes in microRNAs (miRNAs). Over the past several decades, the molecular mechanisms of tumorigenesis, progression and metastasis of lung cancer remain unclear, in spite of a large number of research studies. New and effective therapies are still lacking. Given the high mortality of lung cancer, a better understanding of the mechanisms that underlie lung carcinogenesis is needed.

miRNAs are a class of small endogenous posttranscriptional regulatory non-coding RNAs (containing 22 nucleotides), first discovered by Lee et al (4) in 1993. Primary miRNAs capped with a specially modified nucleotide at the $5^{\prime}$ end and polyadenylated with multiple adenosines [a poly(A) tail] are transcribed by RNA polymerases II $(5,6)$ and then processed in the nucleus by Drosha and Pasha to generate hairpin loop pre-miRNAs composed of $\sim 70$ nucleotides each. Subsequently, the pre-miRNA is exported out of the nucleus into the cytoplasm in a process involving the nucleocytoplasmic shuttler Exportin-5, which is dependent on RAN-GTP (7). In the cytoplasm, the pre-miRNA hairpin is cleaved by the RNase III enzyme Dicer, yielding an 
miRNA:miRNA* duplex 22 nucleotides in length (8). One strand is then incorporated into the RNA-induced silencing complex (RISC), where the miRNA and its mRNA target interact. The interaction of miRNAs with mRNAs normally results in the cleavage or translation inhibition of the target mRNA by binding to the 3 ' untranslated regions.

miRNAs are involved in a large number of biological processes, including cell proliferation, apoptosis, metabolism, cell differentiation and others (9-11). Moreover, abundant evidence has shown that dysfunction of miRNAs is associated with various human diseases, including cancer (12), and a recent study showed that miRNAs can function not only as oncogenes but also as tumor suppressors (13). Over the past several years, several experiments have quantified miRNAs in lung cancer tissues and several dysregulated miRNAs have been revealed: let-7, miR-17-92 cluster, miR-155, miR-145 and hsa-miR-21 (14).

The miR-212/132 family is highly conserved in vertebrates. miR-132 and miR-212 genes are arrayed in tandem on chromosome $17 \mathrm{p} 13.3$ in humans, which is referred to as the miR-212/132 cluster. Therefore, miR-132 and miR-212 are transcribed simultaneously to the primary product pri-miRNA-212/132 in the form of a gene cluster. Then, pri-miRNA-212/132 is processed and cleaved to the mature miRNAs (15). Mature miR-132 and miR-212 possess similar sequences and share the same seed region (a region located between nucleotides 2 and 8 in the 5 region of the miRNA), suggesting that they target the same mRNAs. Nevertheless, this 'double-targeting' by both miRNAs has been reported for only a few mRNAs to date and most of the mRNAs are singly targeted (16).

Numerous studies have shown that the miR-212/132 cluster is necessary for the proper development, maturation and function of neurons. Therefore, its dysregulation is the cause of several neurological disorders, such as Alzheimer's disease. In addition, it can regulate circadian rhythms and is involved in inflammation, immune progress, and drug addiction (16). Recently, miR-212/132 was found to be dysregulated in many cancers and many studies have begun to focus on its biological roles in cancers. Zhang et al (17) discovered that miR-132 was decreased in pancreatic cancer and that it could suppress the proliferation of pancreatic cancer cells through the Akt pathway. However, there are few reports on the potential function of miR-212/132 in the progression of other human cancers, including lung cancer. Therefore, in the present study, we investigated the role of the miR-212/132 cluster in modulating lung cancer progression. Our study may provide insight into the biological function of the miR-212/132 cluster in lung cancer.

\section{Materials and methods}

miR-212/132 overexpression vector and inhibitors. The miR-212/132 overexpression vector (pLMP-miR-212/132) and control vector plasmid (pLMP) were constructed and verified by Huaan Pingkang Biotech Co., Ltd. (Shenzhen, China). The miRNA inhibitor targeting miR-132 and miR-212 (miR-212/132 inhibitor) and the negative inhibitor (NC inhibitor) were obtained from GenePharma (Shanghai, China).
Cell culture. Human lung cancer cell lines A549 and H1299 were cultured in Dulbecco's modified Eagle's medium (DMEM) supplemented with $10 \%$ fetal bovine serum (FBS), $100 \mu \mathrm{g} / \mathrm{ml}$ streptomycin, and $100 \mathrm{U} / \mathrm{ml}$ penicillin (Gibco, Grand Island, NY, USA). Cells were grown in a $37^{\circ} \mathrm{C}$ incubator with $5 \% \mathrm{CO}_{2}$.

Cell viability assay. Cell viability was evaluated using the 3-(4,5-dimethylthiazol-2-yl)-2,5-diphenyl-2H-tetrazolium bromide (MTT) assay. Cells were plated in 96-well plates. The next day, the cells were transfected with plasmids or inhibitors according to the experimental design. After $48 \mathrm{~h}$, the cells were then incubated with $20 \mu \mathrm{l}$ MTT $(5 \mathrm{mg} / \mathrm{ml})$ for $4 \mathrm{~h}$. Next, the medium was carefully removed and $100 \mu \mathrm{l}$ DMSO was added to the plates. The optical density (OD) was measured at $570 \mathrm{~nm}$ with a reference wavelength $650 \mathrm{~nm}$ using a microplate reader (Bio-Rad, Hercules, CA, USA).

Focus formation. A549 or H1299 cells were seeded onto 6 -well plates and were then transfected with the indicated vectors. After incubation for $\sim 10$ days, the cells were fixed and stained with crystal violet. Colonies consisting of more than 50 cells were counted using a microscope.

Clonogenic assay of radiosensitivity. Cells transfected with plasmids or inhibitors were plated at different densities. Then, cells were irradiated with $160 \mathrm{kV}$ X-rays at a dose rate of $1.15 \mathrm{~Gy} / \mathrm{min}$ by a biological research irradiator (RadSource Technologies, Suwanee, GA, USA) at various doses. The cells were then grown for $\sim 10$ days to allow for colony formation and were subsequently fixed with methanol and stained using $1 \%$ crystal violet. Colonies containing 50 or more cells were designated as a clone and counted.

Western blotting. Cells were lysed by RIPA lysis buffer on ice for $40 \mathrm{~min}$ and centrifuged at $13,000 \mathrm{rpm}$ for $10 \mathrm{~min}$ at $4^{\circ} \mathrm{C}$. The supernatant was collected and subjected to westernblotting. Cell lysates containing equal amount of protein were fractionated by $10 \%$ SDS-PAGE, and electrically transferred to PVDF membranes (Millipore, Bedford, MA, USA). Then, non-specific binding was blocked with Tris-buffered saline containing $5 \%$ nonfat milk for $1-2 \mathrm{~h}$ at room temperature. Next, the membranes were incubated with the appropriate primary antibody against p21 or cyclin D1 (both from Santa Cruz Biotechnology Inc., Santa Cruz, CA, USA) overnight at a 1:1,000 dilution. After 4 TBST washes, the membranes were then incubated with corresponding horseradish peroxidaseconjugated secondary antibodies at a 1:1,000 dilution for $1 \mathrm{~h}$ at room temperature. Bound secondary antibodies were detected using enhanced chemiluminescence method.

Flow cytometric analysis. A549 or H1299 cells were transfected with the indicated vectors. After $24 \mathrm{~h}$, cells were harvested and fixed overnight with $70 \%$ ice-cold ethanol. Cells were stained with propidium iodide (PI) containing RNase A for $30 \mathrm{~min}$. The distribution of the cell cycle was detected using a flow cytometer (Beckman Coulter Inc., Fullerton, CA, USA). For apoptosis analysis, cells were cultured for $48 \mathrm{~h}$ after transfection. Next, the cells were harvested and washed with ice-cold phosphate-buffered saline (PBS), and then stained 
A

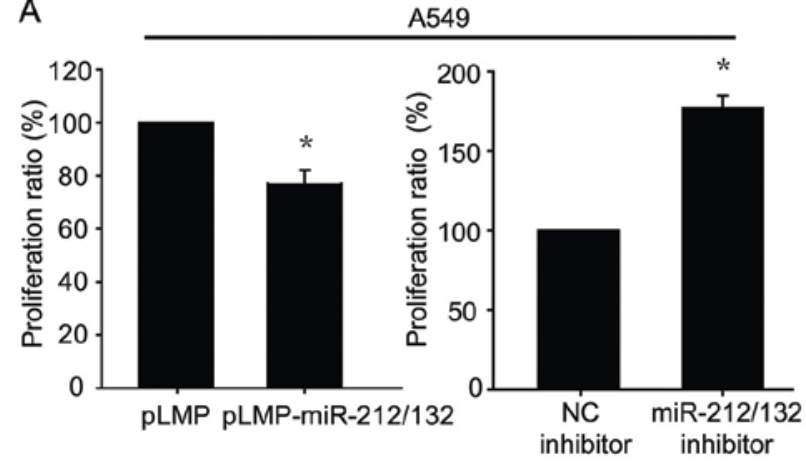

pLMP pLMP-miR-212/132 NC inhibitor miR-212/132

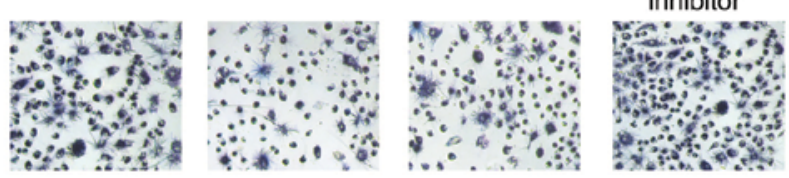

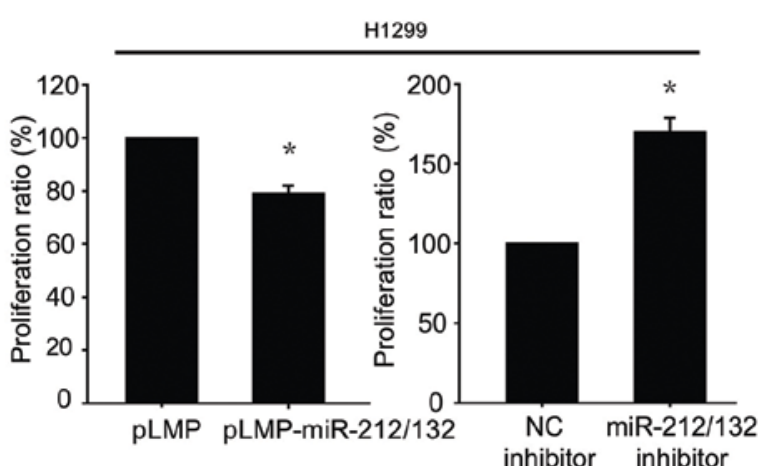

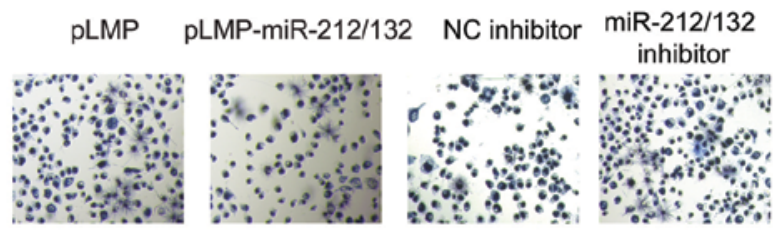

B

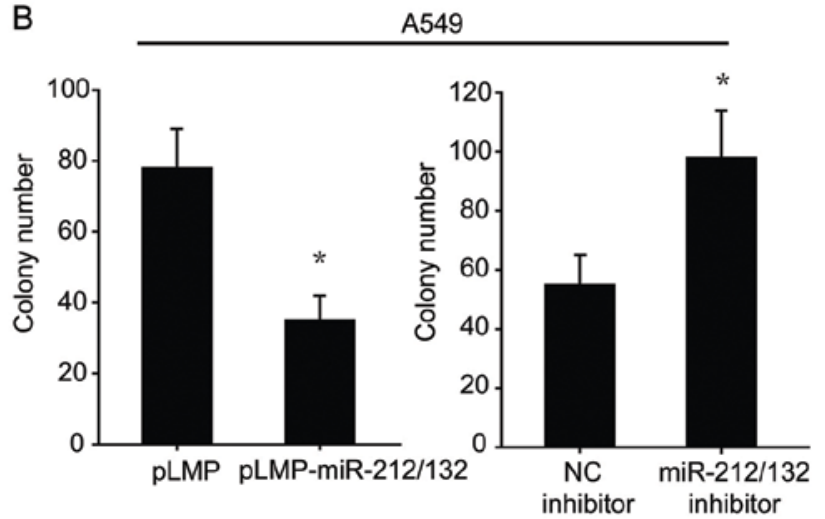

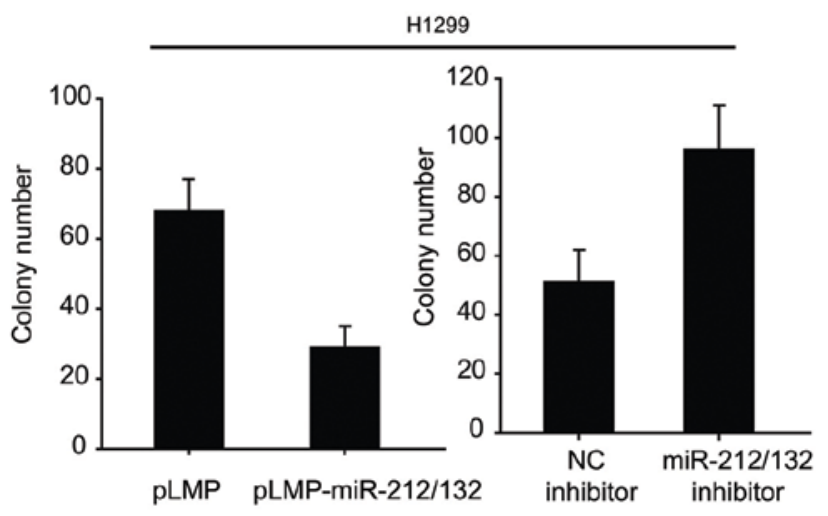

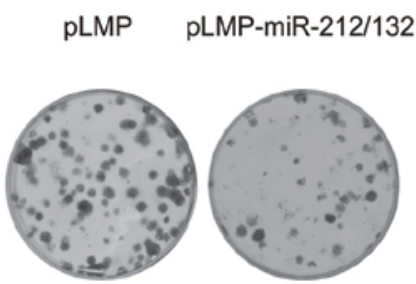

NC inhibitor

miR-212/132 inhibitor

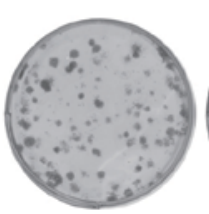

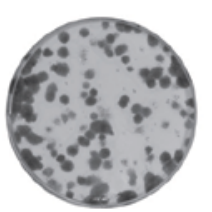

Figure 1. Effect of miR-212/132 on cell proliferation and focus formation. (A) The proliferation of A549 and H1299 cells transfected with indicated vector was examined by MTT assay. (B) Colony formation assays of A549 or H1299 cells transfected with indicated vector. Data are presented as the means \pm standard error of the mean (SEM) and were normalized to the control cells. ${ }^{*} \mathrm{P}<0.05$.

using the Annexin V-phycoerythrin/7-aminoactinomycin D apoptosis detection kit (BD Biosciences, San Jose, CA, USA). The percentage of apoptotic cells was also measured by a flow cytometer within $1 \mathrm{~h}$.

Wound healing assay. H1299 cells were transfected with the indicated vectors. Similar sized wounds were made by scraping a conventional 10- $\mu 1$ micropipette tip across the monolayer. The cells were washed three times with PBS and then DMEM was added without FBS to the plates. The distance between the wound edges was observed and photographed immediately after wounding and $24 \mathrm{~h}$ later. The distance between the wound edges was evaluated using ImageJ software (NIH, Bethesda, MD, USA) and expressed as a percentage of the initial wound distance.
Statistical analysis. Data are expressed as the mean \pm standard error of the mean (SEM) of at least three independent experiments. Analysis was performed using the Student's t-test. The sensitizer enhancement ratios (SER) were measured according to the multi-target single hit model. Statistical analysis was performed using SPSS software (Release 18.0; SPSS Inc., San Rafael, CA, USA). Data were considered statistically significant at $\mathrm{P}<0.05$.

\section{Results}

miR-212/132 suppresses the proliferation of lung cancer cells in vitro. To investigate the effect of miR-212/132 on the proliferation of lung cancer cells, an miR-212/132-overexpressing vector (pLMP-miR-212/132) or a control vector ( $\mathrm{pLMP}$ ) 
A A549
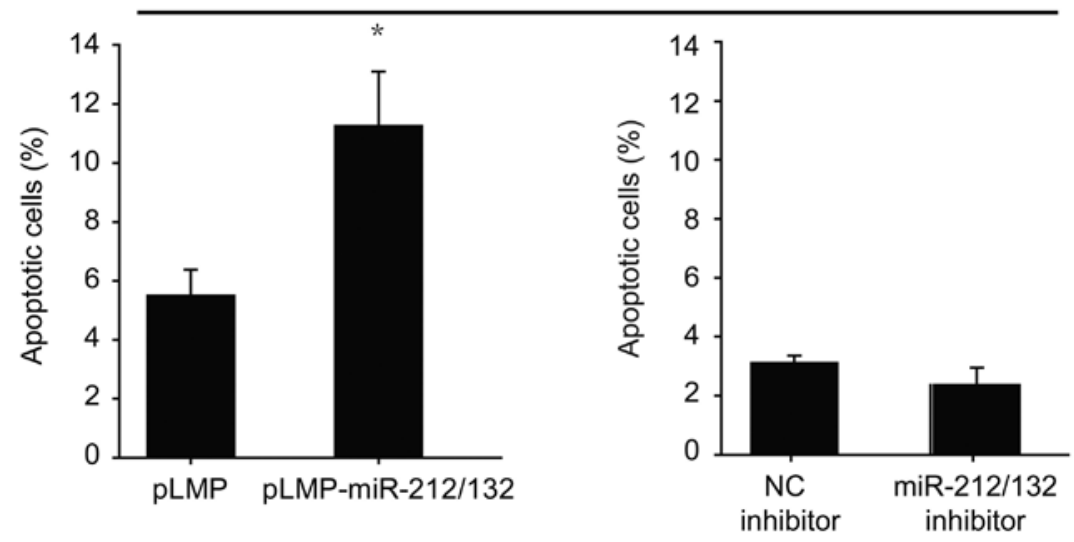

B

$\mathrm{H} 1299$
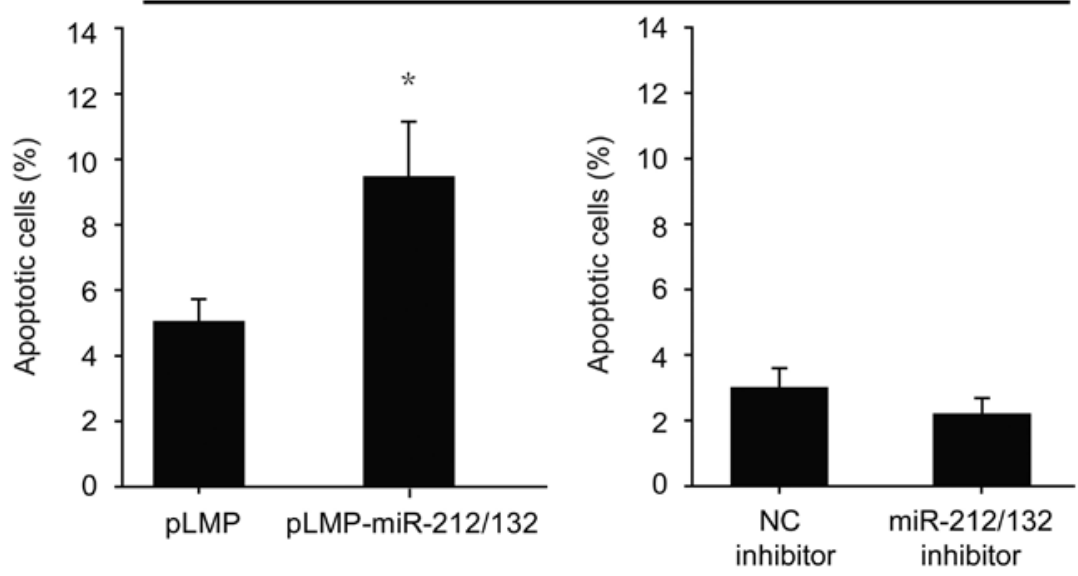

Figure 2. miR-212/132 increases the cell apoptosis of lung cancer cells. A549 (A) and H1299 (B) cells were transfected using the indicated vectors. Two days after transfection, the percentage of apoptotic cells was evaluated using flow cytometry. ${ }^{*} \mathrm{P}<0.05$, compared to the control cells.

were transiently transfected into A549 and H1299 cells, and the resulting growth was measured with MTT and colony formation assays. The results of MTT and colony formation assays revealed that upregulation of miR-212/132 suppressed the growth and focus formation of A549 and H1299 cells, compared to the corresponding controls (Fig. 1). We further inhibited miR-212/132 expression using an inhibitor. The downregulation of miR-212/132 promoted cell proliferation and colony formation (Fig. 1).

miR-212/132 increases the cell apoptosis of lung cancer cells. To investigate the changes in cell apoptosis of lung cancer cells treated with miR-212/132, cells were stained with Annexin V-phycoerythrin/7-aminoactinomycin D and subjected to flow cytometric analysis. As shown in Fig. 2, treatment of miR-212/132 induced a substantial increase in the apoptotic rate when compared to this rate in the corresponding control groups. The downregulation of miR-212/132 decreased cell apoptosis but the difference was not statistically significant (Fig. 2).

miR-212/132 induces cell cycle arrest. To investigate the effects of miR-212/132 on cell cycle progression, flow cytometric analysis was used to observe the cell cycle distribution $24 \mathrm{~h}$ after transfection. miR-212/132 led to an increase in the percentage of cells in G1 phase compared with the control group, and this cell cycle arrest was relieved when the miR-212/132 inhibitor was transfected (Fig. 3A). Next, we analyzed the expression of p21 and cyclin D1, which are implicated in cell cycle progression. As shown in Fig. 3B, cells transfected with miR-212/132 exhibited upregulated p21 expression and reduced cyclin D1 expression. Conversely, cells transfected with the miR-212/132 inhibitor displayed reduced expression of p21 and upregulated expression of cyclin D1, indicating that miR-212/132 inhibits the cell cycle progression of lung cancer.

miR-212/132 transfection diminishes the migration of H1299 cells. The wound healing assay was employed to investigate the correlation between miR-212/132 and H1299 cell migration. The results indicated that miR-212/132 inhibited the migration of H1299 cells compared to the control group (Fig. 4). Conversely, cells transfected with the miR-212/132 inhibitor showed enhanced migration (Fig. 4). These data suggest that miR-212/132 inhibited the migration, which could be reversed by the miR-212/132 inhibitor.

miR-212/132 enhances the radiosensitivity of H1299 cells. To investigate the effect of miR-212/132 on the radiosensitivity of H1299 cells, cells transfected with the different vectors were irradiated with different X-ray doses, and clonogenic assays 
A

A549

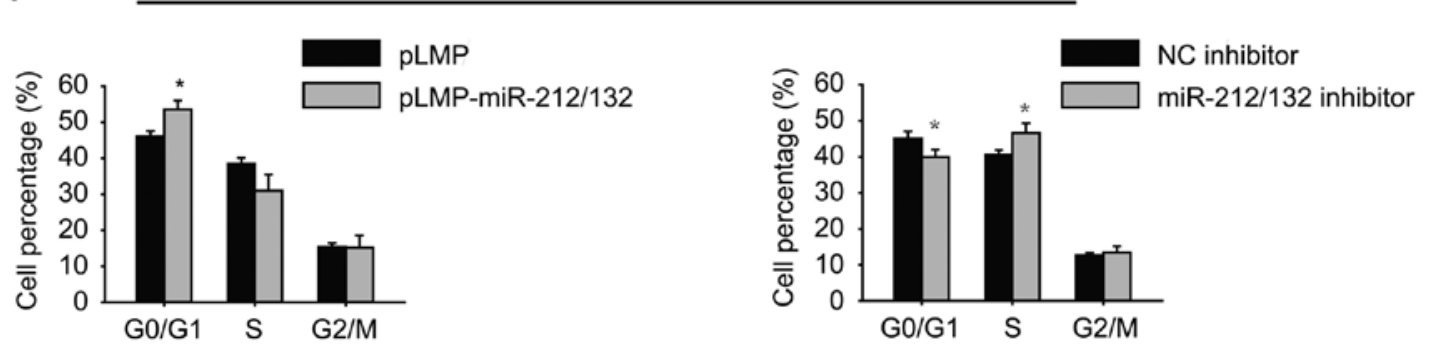

$\mathrm{H} 1299$
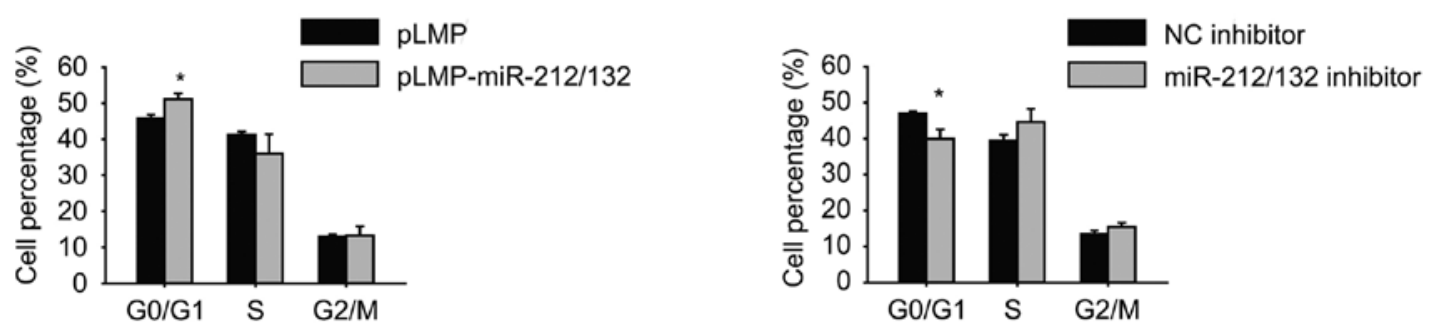

B

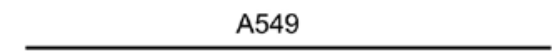

H1299

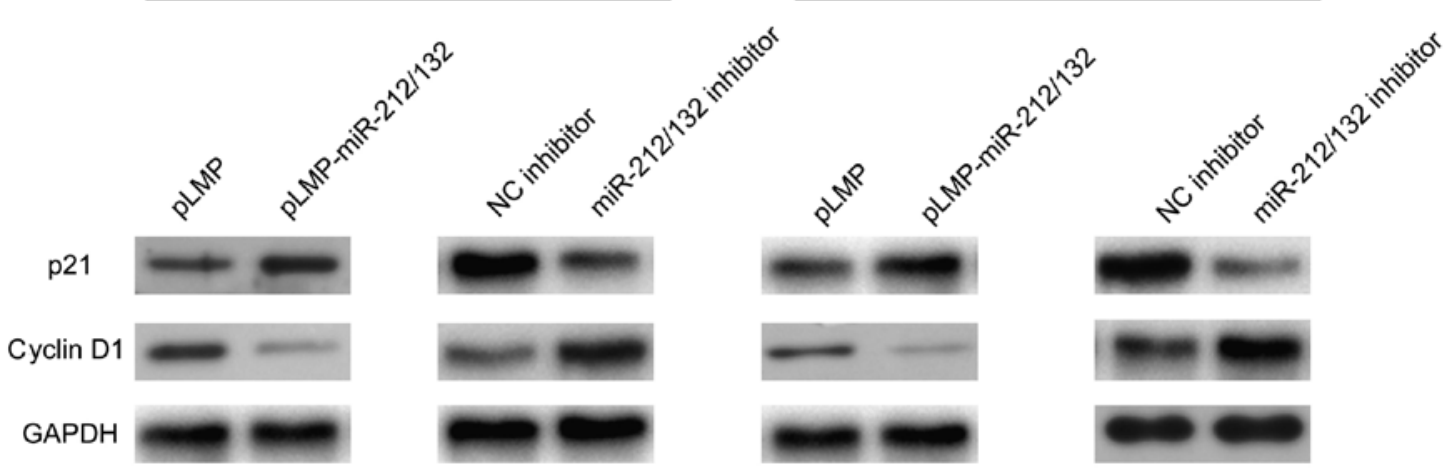

Figure 3. miR-212/132 induces cell cycle arrest. (A) Cell cycle distribution of A549 or H1299 cells was measured using flow cytometry. "P<0.05, compared to the control cells. (B) Western blot analysis of the protein levels of p21 and cyclin D1 in the A549 and H1299 cells.

were performed. As shown in Fig. 5, cells that were transiently transfected with pLMP-miR-212/132 exhibited lower clonogenic survival rates than cells treated with radiation alone, indicating that miR-212/132 enhanced the radiosensitivity of H1299 cells. Next, we transfected the miR-212/132 inhibitor into H1299 cells, and found that the cells became resistant to radiation (Fig. 5).

\section{Discussion}

In recent years, many groups have focused on the molecular mechanisms of lung cancer development, including miRNAs. miRNAs are involved in the formation and progression of lung cancer and their expression profiles have been used to classify cancers and their signature predicts survival and relapse in lung cancer $(18,19)$. In addition, it was revealed that miRNAs participate in multiple biological processes of lung cancer, including proliferation, apoptosis, development and metastasis. Song et al (20) found that miR-483-5p promotes the invasion and migration of lung adenocarcinoma by targeting RhoGDI1 and ALCAM. Yoo et al (21) reported that miR-9500 inhibited the proliferation and migration of human lung cancer cells by targeting Akt1. Shi et al (22) showed that miR-34a was a negative regulator of the tumorigenic properties of NSCLC cells and inhibited their growth.

miR-132 expression has been reported to be increased in several types of cancers including lung cancer (14), squamous cell carcinoma of the tongue (23), colorectal carcinoma (24) and esophageal cancer (25). However, decreased miR-132 expression has been observed in osteosarcoma (26) and liver cancer (27). Increased miR-212 expression was reported in oral squamous cell carcinoma (28) and colorectal carcinoma (23), and miR-212 has been shown to be downregulated in gastric cancer (29), NSCLC (30) and head and neck squamous cell carcinoma (31). The different levels of expression of these miRNAs in various cancers indicate that they may exert diverse functions in cancer cells. To our knowledge, no report has taken an in-depth look into the role of miR-212/132 in lung cancer cells.

In the present study, we found that upregulation of miR-212/132 significantly suppressed the growth and focus 
A
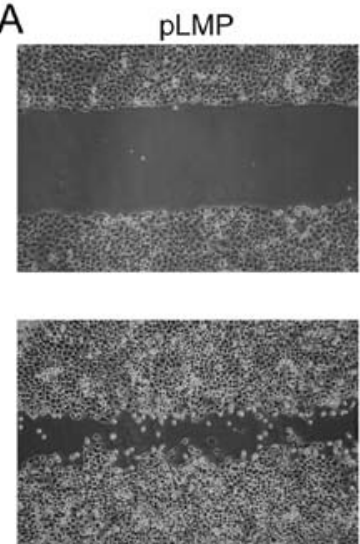

NC inhibitor
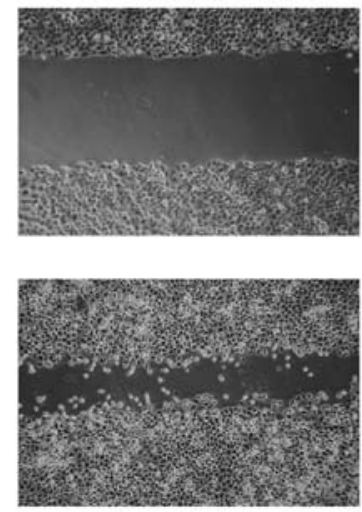

pLMP-miR-212/132
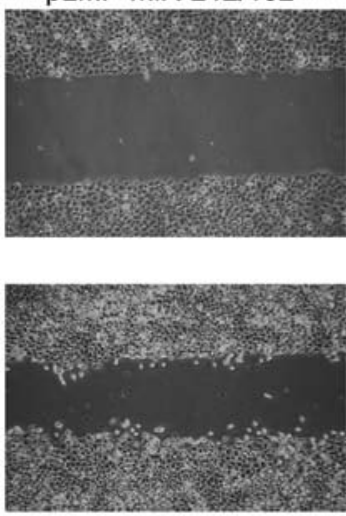

miR-212/132 inhibitor
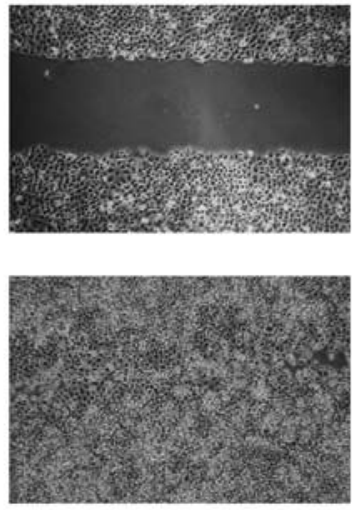

Oh

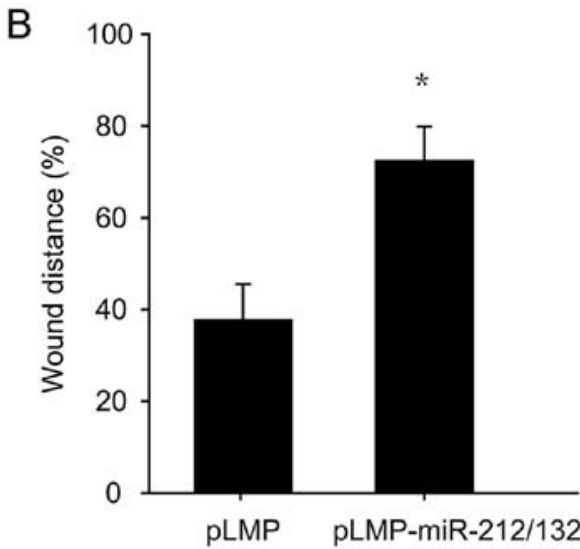

$24 \mathrm{~h}$

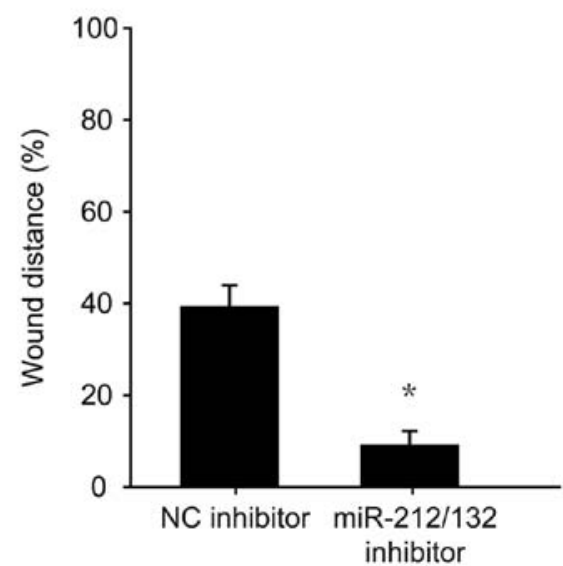

Figure 4. miR-212/132 transfection diminishes the migration of H1299 cells. (A) Wound healing assay was performed $24 \mathrm{~h}$ after plating, and the distance between the wound edges was observed and photographed. (B) The distance between the wound edges was evaluated using ImageJ and is expressed as the percentage of the initial wound distance. ${ }^{*} \mathrm{P}<0.05$, compared to the control cells.

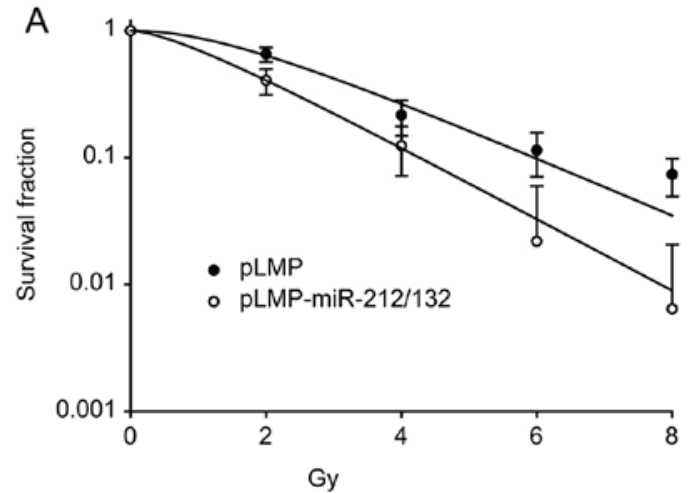

B

\begin{tabular}{ccccc}
\hline & D0 & Dq & N & SER \\
\hline $\begin{array}{c}\text { pLMP } \\
\text { pLMP- }\end{array}$ & 1.80 & 1.53 & 2.56 & \\
miR-212/132 & 1.52 & 0.93 & 1.67 & \\
& & & & 1.64
\end{tabular}

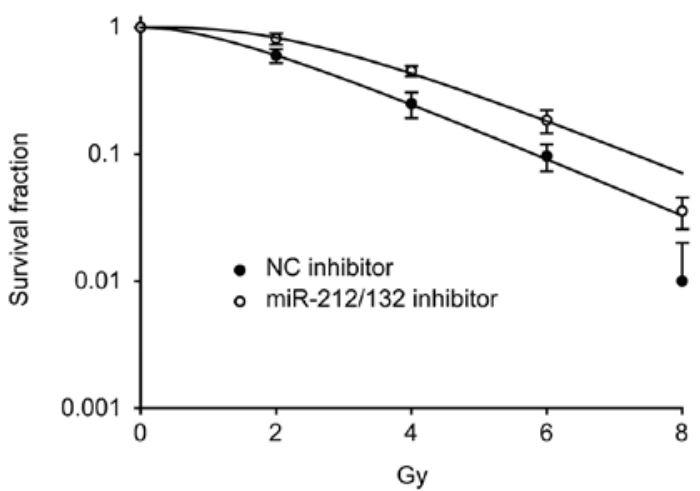

\begin{tabular}{ccccc}
\hline & $\mathrm{D}_{0}$ & $\mathrm{Dq}$ & $\mathrm{N}$ & $\mathrm{SER}$ \\
\hline $\begin{array}{c}\text { NC-inhibitor } \\
\text { miR-212/132 } \\
\text { inhibitor }\end{array}$ & 1.91 & 1.40 & 2.13 & \\
& 2.02 & 2.04 & 3.81 & \\
\hline
\end{tabular}

Figure 5. miR-212/132 enhances the radiosensitivity of the H1299 cells. (A) Clonogenic cell survival curves were generated. (B) Radiobiological parameters were calculated.

formation of A549 and H1299 cells and conferred radiosensitivity to H1299 cells, whereas downregulation of miR-212/132 reversed these effects. Furthermore, miR-212/132 overexpression induced cell cycle arrest at the G1/S phase transition 
of A549 and H1299 cells, and the miR-212/132 inhibitor abrogated this arrest. Therefore, the inhibition of cellular proliferation by overexpression of miR-212/132 may be due to restrained cancer cell division. In addition, the miR-212/132 overexpression group exhibited a higher percentage of cells that underwent apoptosis, which may also lead to the inhibiiton of growth and colony formation. To identify the molecular mechanism, p21 and cyclin D1 were detected at the protein level in each group and we discovered that cells transfected with miR-212/132 had upregulated p21 expression and reduced cyclin D1 expression. Conversely, cells transfected with the miR-212/132 inhibitor displayed reduced expression of p21 and upregulated expression of cyclin D1, suggesting that miR-212/132 may mediate proliferation and cell cycle arrest through p21 and cyclin D1 (32).

You et al (33) found that miR-132 suppressed the migration of lung cancer cells by targeting the EMT regulator ZEB2. Therefore, we hypothesized that miR-212/132 may also suppress the migration of lung cancer cells. As expected, upregulation of miR-212/132 diminished the migration of H1299 cells and downregulation of miR-212/132 enhanced their migration.

The predicted targets of miR-132 and miR-212 include hundreds of genes implicated in multiple pathways. These targets may be the upstream of Akt, including ACVR2B, ACVR1, connective tissue growth factor, HB-EGF $(31,34)$, GTPase-activating proteins [p120RasGAP (35) and p250GAP (36,37)], Rb1 (38), STAT4 (39) and ZO-1 (40). We did not investigate the direct targets of miR-132 and miR-212, in part because the roles of the predicted targets listed above in lung cancer progression are not clear, which warrants further investigation. Additionally, since each miRNA can regulate numerous protein-coding genes, its functions can be interpreted as the sum of the functions of the genes it regulates (41). Therefore, we considered it more important to analyze the consequences of miR-212/132 dysregulation in lung cancer progression.

In conclusion, we illustrated the biological role of miR-212/132 in lung cancer cells. Our findings suggest that miR-212/132 may be a novel tumor-suppressor miRNA. miR-212/132 blocked proliferation and migration, and led to cell cycle arrest of lung cancer cells through modulating the expression of p21 and cyclin D1. This study may provide a potential therapeutic target for the treatment of lung cancer.

\section{Acknowledgements}

This study as funded by the National Natural Science Foundation of China (81402518 and 81472920), the Jiangsu Provincial Special Program of Medical Science (BL2012046), the Changzhou Social Development Project (CE20125026 and CE20135050) and the Changzhou Scientific Program (ZD201315 and CY20130017).

\section{References}

1. Jemal A, Bray F, Center MM, Ferlay J, Ward E and Forman D: Global cancer statistics. CA Cancer J Clin 61: 69-90, 2011.

2. Ramalingam S and Belani C: Systemic chemotherapy for advanced non-small cell lung cancer: recent advances and future directions. Oncologist 13 (Suppl 1): s5-s13, 2008.
3. Chaffer CL and Weinberg RA: A perspective on cancer cell metastasis. Science 331: 1559-1564, 2011.

4. Lee RC, Feinbaum RL and Ambros V: The C.elegans heterochronic gene lin-4 encodes small RNAs with antisense complementarity to lin-14. Cell 75: 843-854, 1993.

5. Lee Y, Kim M, Han J, et al: MicroRNA genes are transcribed by RNA polymerase II. EMBO J 23: 4051-4060, 2004.

6. Cai X, Hagedorn $\mathrm{CH}$ and Cullen BR: Human microRNAs are processed from capped, polyadenylated transcripts that can also function as mRNAs. RNA 10: 1957-1966, 2004.

7. Murchison EP and Hannon GJ: miRNAs on the move: miRNA biogenesis and the RNAi machinery. Curr Opin Cell Biol 16: 223-229, 2004

8. Lund E and Dahlberg JE: Substrate selectivity of exportin 5 and Dicer in the biogenesis of microRNAs. Cold Spring Harb Symp Quant Biol 71: 59-66, 2006.

9. Bueno MJ, Pérez de Castro I and Malumbres M: Control of cell proliferation pathways by microRNAs. Cell Cycle 7: 3143-3148, 2008.

10. Wang Y and Lee CG: MicroRNA and cancer - focus on apoptosis. J Cell Mol Med 13: 12-23, 2009.

11. Chen CZ, Li L, Lodish HF and Bartel DP: microRNAs modulate hematopoietic lineage differentiation. Science 303: 83-86, 2004.

12. Wang D, Qiu C, Zhang H, Wang J, Cui Q and Yin Y: Human microRNA oncogenes and tumor suppressors show significantly different biological patterns: from functions to targets. PLoS One 5: e13067, 2010.

13. Chen CZ: microRNAs as oncogenes and tumor suppressors. N Engl J Med 353: 1768-1771, 2005.

14. Yanaihara N, Caplen N, Bowman E, et al: Unique microRNA molecular profiles in lung cancer diagnosis and prognosis. Cancer Cell 9: 189-198, 2006.

15. Tognini $\mathrm{P}$ and Pizzorusso T: MicroRNA212/132 family: molecular transducer of neuronal function and plasticity. Int J Biochem Cell Biol 44: 6-10, 2012.

16. Wanet A, Tacheny A, Arnould T and Renard P: miR-212/132 expression and functions: within and beyond the neuronal compartment. Nucleic Acids Res 40: 4742-4753, 2012.

17. Zhang S, Hao J, Xie F, et al: Downregulation of miR-132 by promoter methylation contributes to pancreatic cancer development. Carcinogenesis 32: 1183-1189, 2011.

18. Lu J, Getz G, Miska EA, et al: MicroRNA expression profiles classify human cancers. Nature 435: 834-838, 2005.

19. Yu SL, Chen HY, Chang GC, et al: MicroRNA signature predicts survival and relapse in lung cancer. Cancer Cell 13: 48-57, 2008.

20. Song Q, Xu Y, Yang C, et al: miR-483-5p promotes invasion and metastasis of lung adenocarcinoma by targeting RhoGDI1 and ALCAM. Cancer Res 74: 3031-3042, 2014.

21. Yoo JK, Jung HY, Lee JM, et al: The novel miR-9500 regulates the proliferation and migration of human lung cancer cells by targeting Akt1. Cell Death Differ 21: 1150-1159, 2014

22. Shi Y, Liu C, Liu X, Tang DG and Wang J: The microRNA miR-34a inhibits non-small cell lung cancer (NSCLC) growth and the CD44hi stem-like NSCLC cells. PLoS One 9: e90022, 2014.

23. Wong TS, Liu XB, Wong BY, Ng RW, Yuen AP and Wei WI: Mature miR-184 as potential oncogenic microRNA of squamous cell carcinoma of Tongue. Clin Cancer Res 14: 2588-2592, 2008.

24. Schetter AJ, Leung SY, Sohn JJ, et al: MicroRNA expression profiles associated with prognosis and therapeutic outcome in colon adenocarcinoma. JAMA 299: 425-436, 2008.

25. Ogawa R, Ishiguro H, Kuwabara Y, et al: Expression profiling of micro-RNAs in human esophageal squamous cell carcinoma using RT-PCR. Med Mol Morphol 42: 102-109, 2009.

26. Gougelet A, Pissaloux D, Besse A, et al: Micro-RNA profiles in osteosarcoma as a predictive tool for ifosfamide response. Int J Cancer 129: 680-690, 2011.

27. Meng F, Henson R, Wehbe-Janek H, Ghoshal K, Jacob ST and Patel T: MicroRNA-21 regulates expression of the PTEN tumor suppressor gene in human hepatocellular cancer. Gastroenterology 133: 647-658, 2007.

28. Scapoli L, Palmieri A, Lo Muzio L, et al: MicroRNA expression profiling of oral carcinoma identifies new markers of tumor progression. Int J Immunopathol Pharmacol 23: 1229-1234, 2010.

29. Wada R, Akiyama Y, Hashimoto Y, Fukamachi H and Yuasa Y: miR-212 is downregulated and suppresses methyl-CpG-binding protein $\mathrm{MeCP} 2$ in human gastric cancer. Int J Cancer 127: 1106-1114, 2010 
30. Incoronato M, Garofalo M, Urso L, et al: miR-212 increases tumor necrosis factor-related apoptosis-inducing ligand sensitivity in non-small cell lung cancer by targeting the antiapoptotic protein PED. Cancer Res 70: 3638-3646, 2010.

31. Hatakeyama H, Cheng H, Wirth P, et al: Regulation of heparinbinding EGF-like growth factor by miR-212 and acquired cetuximab-resistance in head and neck squamous cell carcinoma. PLoS One 5: e12702, 2010.

32. Gartel AL and Radhakrishnan SK: Lost in transcription: $\mathrm{p} 21$ repression, mechanisms and consequences. Cancer Res 65: 3980-3985, 2005.

33. You J, Li Y, Fang N, et al: MiR-132 suppresses the migration and invasion of lung cancer cells via targeting the EMT regulator ZEB2. PLoS One 9: e91827, 2014.

34. Molnár V, Érsek B, Wiener Z, et al: MicroRNA-132 targets HB-EGF upon IgE-mediated activation in murine and human mast cells. Cell Mol Life Sci 69: 793-808, 2012.

35. Anand S, Majeti BK, Acevedo LM, et al: MicroRNA-132mediated loss of p120RasGAP activates the endothelium to facilitate pathological angiogenesis. Nat Med 16: 909-914, 2010.
36. Vo N, Klein ME, Varlamova O, et al: A cAMP-response element binding protein-induced microRNA regulates neuronal morphogenesis. Proc Natl Acad Sci USA 102: 16426-16431, 2005.

37. Wayman GA, Davare M, Ando H, et al: An activity-regulated microRNA controls dendritic plasticity by downregulating p250GAP. Proc Natl Acad Sci USA 105: 9093-9098, 2008.

38. Park JK, Henry JC, Jiang J, et al: miR-132 and miR-212 are increased in pancreatic cancer and target the retinoblastoma tumor suppressor. Biochem Biophys Res Commun 406: 518-523, 2011.

39. Huang Y, Lei Y, Zhang H, Hou L, Zhang M and Dayton AI: MicroRNA regulation of STAT4 protein expression: rapid and sensitive modulation of IL-12 signaling in human natural killer cells. Blood 118: 6793-6802, 2011.

40. Tang Y, Banan A, Forsyth CB, et al: Effect of alcohol on miR-212 expression in intestinal epithelial cells and its potential role in alcoholic liver disease. Alcohol Clin Exp Res 32: 355-364, 2008.

41. Sonkoly E, Wei T, Janson PC, et al: microRNAs: novel regulators involved in the pathogenesis of psoriasis? PLoS One 2: e610, 2007. 